\title{
UTILIZAÇÃO DE RESÍDUOS DA CONSTRUÇÃO CIVIL E CINZA DO BAGAÇO DE CANA-DE-AÇÚCAR PARA A PRODUÇÃO DE ARGAMASSA DE REVESTIMENTO
}

\author{
Sergio Tunis Martins Filho* \\ José Aparecido Canova** \\ Nayara Soares Klein ${ }^{* * *}$ \\ Victor Podanoschi Peixoto****
}

RESUMO: Investiga-se a potencialidade de reutilização dos resíduos da construção civil (RCC) e da cinza do bagaço de cana-de-açúcar (CBC) para a produção de argamassa de revestimento em substituição total do agregado miúdo (areia natural quartzosa), em diferentes porcentagens, com o intuito de prover uma destinação final adequada a estes materiais e de refrear a extração e uso da areia como agregado miúdo. A análise da argamassa em estudo foi realizada comparando-a com as características obtidas para um traço de referência composto de cimento e areia. Produziram-se argamassas de revestimento substituindo totalmente o volume de agregado miúdo em cinco diferentes composições: $100 \%$ de $\mathrm{CBC}, 75 \%$ de $\mathrm{CBC}$ e $25 \%$ de RCC, $50 \%$ de CBC e $50 \%$ de RCC, $25 \%$ de CBC e $75 \%$ de RCC e $100 \%$ de RCC. Os resultados dos ensaios da argamassa no estado fresco e endurecido mostraram a viabilidade de utilização destes materiais, que além de melhorar o desempenho mecânico e manter a retenção de água, promovem uma contribuição sustentável. Destaca-se que o traço com 75\% RCC e 25\% CBC apresentou melhor resistência à tração e compressão.

PALAVRAS-CHAVE: Argamassa de revestimento; Resíduos; Sustentabilidade.

\footnotetext{
Docente no departamento de engenharia civil Universidade Tecnológica Federal do Paraná (UTFPR/ Apucarana). Doutorando em Engenharia de Construção Civil pela Universidade Federal do Paraná (UFPR), Brasil. E-mail: sergiotunis@hotmail.com

** Docente no departamento de engenharia civil Universidade Estadual de Maringá (UEM). Doutor em Engenharia Química pela Universidade Estadual de Maringá (UEM), Brasil.

*** Docente no departamento de engenharia civil Universidade Federal do Paraná (UFPR). Doutora em Engenharia da Construção pelo Universitat Politècnica de Catalunya, Espanha.

${ }^{* * * *}$ Graduado em engenharia civil pela na Universidade Estadual de Maringá (UEM), Brasil.
} 


\section{THE USE OF RESIDUES OF CIVIL CONSTRUCTION AND ASHES FROM SUGAR CANE BAGASSE FOR THE PRODUCTION OF FINISHING MORTAR}

ABSTRACT: The reuse of civil construction wastes (CCW) and sugar cane bagasse (CCB) for the production of finishing mortar to replace totally small aggregates (natural sand), at different percentages, is investigated. In fact, their adequate disposal diminishes the extraction and use of sand as aggregate. Mortar was compared with the characteristics derived from a compound made of cement and sand. Finishing mortar was produced and totally replaced the small aggregates in five different compositions: 100\% CCB; 75\% CCB and 25\% CCW; 50\% CCB and $50 \%$ CCW; 25\% CCB and 75\% CCW and 100\% CCW. Result of assay with fresh and hardened mortar revealed the feasibility of employing this material. Mechanical performance was improved and water retention was maintained and, consequently, a sustainable contribution. Treatment $75 \% \mathrm{CCW}$ and 25\% CCB provided the best resistance for traction and compression.

KEY WORDS: Finishing mortar; Residues; Sustainability.

\section{INTRODUÇÃO}

A construção civil é uma das atividades mais antigas praticadas pelo homem e desde os primórdios da humanidade, mesmo sendo executada de forma artesanal, gerava como subprodutos grandes quantidades de entulhos minerais (LEVY; HELENE, 2000).

Entretanto, é necessário que mudanças sejam estudadas e aplicadas na construção civil, pois esta destaca-se como uma atividade promotora de impactos ambientais e seus resíduos têm representado um grande problema não só no meio ambiente, mas também na vida da população (FREITAS, 2009). Tais problemas ambientais referentes aos resíduos de construção e demolição estão relacionados à sua disposição final e à exploração de matérias-primas (MARIANO, 2008).

De acordo com a Associação Brasileira para Reciclagem de Resíduos da Construção Civil e Demolição (ABRECON, 2016) o RCC é todo resíduo gerado no processo construtivo, de reforma, escavação ou demolição. Os resíduos, também 
conhecidos como entulhos, envolvem principalmente conjunto de fragmentos ou restos de tijolo, concreto, argamassa, aço e madeira.

Além do reaproveitamento do RCC em substituição a insumos básicos na construção civil, outros materiais vêm sendo estudados com a finalidade de preservar matéria-prima natural. Vale destacar, por exemplo, que a atividade de extração de areia para emprego na construção civil é considerada como de potencial degradador médio, pois sua extração é responsável por alterações na paisagem e nos diferentes tipos de leitos e de suas dinâmicas, por meio de erosão em margens de rios, emissão de material particulado, e outros impactos ambientais (OLIVEIRA et al., 2012).

Neste contexto, a cana-de-açúcar também surge como um produto em potencial de estudo, visto que é uma das principais culturas do mundo, e cerca de $80 \%$ da produção do planeta estão concentradas em dez países, sendo o Brasil o líder mundial (NOVA CANA, 2008). A produção dos subprodutos da cana-de-açúcar, nas Usinas Sucroalcooleiras, gera resíduos agroindustriais, como exemplo, as cinzas do bagaço de cana-de-açúcar (CBC).

As $\mathrm{CBC}$ têm normalmente como destino final seu lançamento no solo, como um suposto adubo (FREITAS, 2009). No entanto, estudos mostram que estas cinzas possuem propriedades físicas e químicas que lhe conferem um destino mais viável, possibilitando, então, serem utilizadas como matérias-primas potenciais na produção de cimentos compostos e de aditivos minerais para pastas, argamassas e concretos (MARTIRENA HERNÁNDEZ et al., 1998; SINGH et al., 2000; PAYÁ et al., 2002 apud CORDEIRO, 2006; MARTINS; ALTOÉ, 2015; MARTINS FILHO; MARTINS, 2017). Essas propriedades resultam em benefícios na reologia, resistência, durabilidade e outros fatores em decorrência do seu emprego (MALHOTRA; MEHTA, 1996; NEVILLE, 1997; MASSAZZA, 1998; SABIR et al., 2001 apud CORDEIRO, 2006; MARTINS; ALTOÉ, 2015; MARTINS FILHO; MARTINS, 2017).

Diante do contexto econômico, social e ambiental que a indústria da construção civil se encontra e da disponibilidade de RCC e CBC, aborda-se nesta pesquisa a inserção destes materiais na produção de argamassas de revestimento, verificando suas potencialidades, além de promover a diminuição da extração de um recurso natural e dar um melhor destino às $\mathrm{CBC}$. 


\section{MATERIAIS E MÉTODOS}

Para a análise do potencial de reutilização dos RCC e CBC, primeiramente foi realizada a coleta dos materiais, o RCC foi obtido no Aterro de Resíduos da Construção Civil no município de Maringá (PR), enquanto que a $\mathrm{CBC}$ foi coletada em uma Usina Sucroalcooleira no município de Iguatemi (PR). A areia natural utilizada foi quartzosa e o cimento utilizado é do tipo CPII-Z.

Para confecção da argamassa, estes materiais foram submetidos ao processo de secagem em estufa e peneiramento utilizando o passante na peneira de $2,4 \mathrm{~mm}$ para o RCC e para areia quartzosa, de modo a uniformizar o agregado miúdo em uma granulometria predominante desses materiais, e o passante na peneira $0,6 \mathrm{~mm}$ para a CBC, o qual permite a separação da matéria orgânica queimada ainda presente. Após o peneiramento foi realizada a caracterização dos materiais por meio do ensaio de granulometria e a determinação do módulo de finura de acordo com a ABNT NBR NM - 248:2003. Os ensaios de massa específica dos materiais foram realizados de acordo com a ABNT NBR NM 52:2009 e para o cimento pela ABNT NBR NM 23:2001. Já a determinação da massa unitária e do volume de vazios de acordo com a ABNT NBRNM 45:2006.

Após a caracterização dos materiais, iniciou-se o processo de produção das argamassas, que foram dosadas, em volume, na proporção de cimento e agregado miúdo de 1:6,84. Este traço foi formulado pelos autores para o estudo. No total seis traços foram estudados, sendo um deles o traço de referência composto de cimento e areia, os outros cinco traços foram feitos substituindo totalmente a areia por $100 \%$ de RCC (T1), $75 \%$ de RCC e $25 \%$ de CBC (T2), $50 \%$ de RCC e $50 \%$ de CBC (T3), $25 \%$ de RCC e $75 \%$ de CBC (T4) e 100\% de CBC (T5). Assim, pôde-se comparar o desempenho dos traços feitos com RCC e/ou CBC com o traço de referência. Para a elaboração dos traços, inicialmente foi necessário determinar o consumo de cimento para argamassas de revestimento, valor estipulado em $160 \mathrm{~kg} / \mathrm{m}^{3}$ de acordo com o método do CETA-BA proposto por Gomes e Neves (2002), em que o consumo de cimento para argamassas de revestimento varia de 160 a $180 \mathrm{~kg} / \mathrm{m}^{3}$. Em seguida, foi determinado o teor de água para obtenção do índice de consistência-padrão de acordo com a ABNT NBR 13276:2005. 
Com o teor de água ideal determinado para cada traço e consequentemente tendo esta argamassa pronta, pôde-se, então, determinar a densidade de massa e o teor de ar incorporado de acordo com a ABNT NBR 13278:2005, e também o ensaio de retenção de água de acordo com ABNT NBR 13277:2005. Por fim, para determinar o desempenho mecânico com a argamassa preparada com o teor de água ideal, foram moldados três corpos de prova prismáticos de acordo com a ABNT NBR 13279:2005.

\section{RESULTADOS}

A Figura 1 e Tabela 1 retratam a análise granulométrica do RCC e da CBC, previamente peneirados na peneira de $2,4 \mathrm{~mm}$ e $0,6 \mathrm{~mm}$, respectivamente.
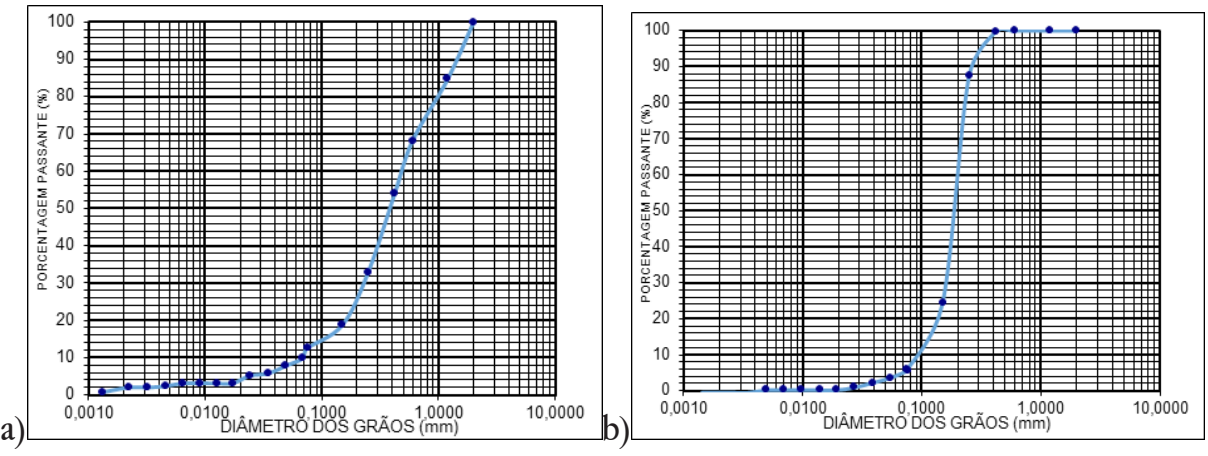

Figura 1. Curva granulométrica a) RCC e b) CBC

Tabela 1. Classificação Granulométrica do RCC e CBC

\begin{tabular}{c|c|c}
\hline Classificação segundo a ABNT & RCC & CBC \\
\cline { 2 - 3 } NBR 6502:1995 & Percentagem retida (\%) & Percentagem retida (\%) \\
\hline 0,6 a $2 \mathrm{~mm}$ (Areia grossa) & 32,00 & 0,00 \\
\hline 0,2 a $0,6 \mathrm{~mm}$ (Areia média) & 40,00 & 46,00 \\
\hline 0,06 a $0,2 \mathrm{~mm}$ (Areia fina) & 20,00 & 51,00 \\
\hline 0,002 a $0,06 \mathrm{~mm}$ (Silte) & 6,00 & 2,50 \\
\hline$\leq 0,002 \mathrm{~mm}$ (Argila) & 2,00 & 0,50 \\
\hline
\end{tabular}


Nota-se que o RCC possui uma fração granulométrica predominante de areia média, enquanto que a $\mathrm{CBC}$ possui uma fração granulométrica predominante como areia fina. As Figuras 2 e 3, abaixo, ilustram o RCC e a CBC, respectivamente.

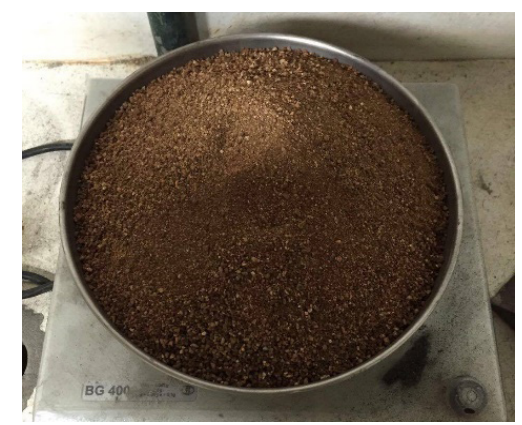

Figura 2. RCC

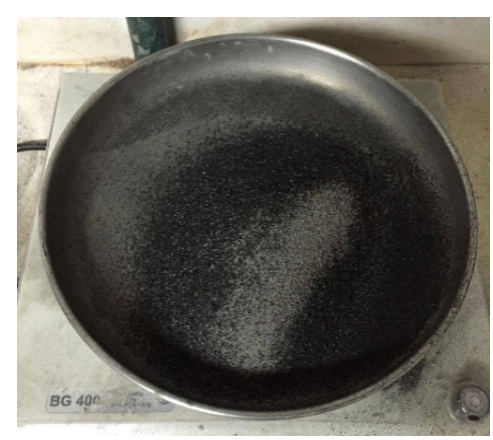

Figura 3. $\mathrm{CBC}$

Na quantificação do teor de finos para os RCC, CBC e areia as porcentagens passantes em 0,075 $\mathrm{mm}$ foram de 12,64\%, 4,61\% e 5,00\%, respectivamente.

Os resultados da massa específica dos RCC, CBC e areia seguem na Tabela 2.

Tabela 2. Massa específica

\begin{tabular}{c|c}
\hline Materiais & Massa específica $\left(\mathrm{g} / \mathrm{cm}^{3}\right)$ \\
\hline Cimento & 2,76 \\
\hline RCC & 2,84 \\
\hline CBC & 2,71 \\
\hline Areia & 2,72 \\
\hline
\end{tabular}


Observa-se pela Tabela 2 que o RCC apresentou um valor de massa específica um pouco superior à massa específica da areia ensaiada e que a $\mathrm{CBC}$ apresenta um valor de massa específica muito próximo à massa específica da mesma.

A massa unitária e volume de vazios dos $\mathrm{RCC}, \mathrm{CBC}$, da areia e do cimento (CPII-Z 32) estão apresentados na Tabela 3.

Tabela 3. Massa unitária dos materiais

\begin{tabular}{c|c|c}
\hline Materiais & Massa unitária $\left(\mathrm{g} / \mathrm{cm}^{3}\right)$ & Volume de vazios $(\%)$ \\
\hline Cimento & 1,24 & 54,89 \\
\hline RCC & 1,26 & 55,45 \\
\hline Areia & 1,47 & 45,69 \\
\hline CBC & 1,10 & 59,20 \\
\hline
\end{tabular}

Os traços das argamassas foram dosados na proporção de cimento e agregado miúdo no traço, em volume, de 1:6,84. No total seis traços foram dosados e produzidos de acordo com a Tabela 4, variando o volume de agregado miúdo.

Tabela 4. Dosagem dos traços de argamassa

\begin{tabular}{c|c|c}
\hline \multicolumn{3}{c}{ Porcentagem agregados miúdo } \\
\hline Traço & RCC $(\%)$ & Cinzas (\%) \\
\hline Referência & 0 & 0 \\
\hline T1 & 100 & 0 \\
\hline T2 & 75 & 25 \\
\hline T3 & 50 & 50 \\
\hline T4 & 25 & 75 \\
\hline T5 & 0 & 100 \\
\hline
\end{tabular}

Para confecção dos traços foi necessário determinar o teor de água para obtenção do índice de consistência-padrão. A argamassa ideal foi a que obteve um espalhamento de $255 \pm 10 \mathrm{~mm}$. Na Tabela 5 seguem os resultados obtidos, assim como o consumo de cimento para o teor de água necessário para sua consistência ideal. 
Tabela 5. Teor de água dos traços de argamassa

\begin{tabular}{c|c|c|c}
\hline Traço & Água adicionada $(\mathbf{m l})$ & Teor de água (\%) & Consumo de cimento $\left.\mathbf{( k g} / \mathbf{m}^{\mathbf{3}}\right)$ \\
\hline Referência & 855,00 & 19 & 180,86 \\
\hline 1 & 760,00 & 19 & 207,62 \\
\hline 2 & 780,00 & 20 & 213,77 \\
\hline 3 & 800,00 & 21 & 220,16 \\
\hline 4 & 880,00 & 24 & 216,09 \\
\hline 5 & 920,00 & 26 & 214,98 \\
\hline
\end{tabular}

Nota-se que o teor de água aumentou proporcionalmente à medida que foi incrementado $\mathrm{CBC}$, destacando que esta possui uma granulometria menor e também um maior volume de vazios, com a tendência do aumento da água de amassamento.

Para cada traço de argamassa foi determinado: i) densidade de massa; ii) teor de ar incorporado; iii) densidade teórica; iv) retenção de água na argamassa; v) relação entre a pasta e os agregados. Os resultados obtidos da densidade de massa seguem na Tabela 6 , densidade teórica na Tabela 7 , teor de ar incorporado, relação de pasta e agregado da argamassa na Tabela 8 , ensaio de retenção de água na Tabela 9.

Tabela 6. Densidade de massa das argamassas

\begin{tabular}{c|c}
\hline Traço & Densidade de massa da argamassa $\left(\mathrm{g} / \mathrm{cm}^{3}\right)$ \\
\hline Ref. & 1,96 \\
\hline T1 & 1,97 \\
\hline T2 & 1,99 \\
\hline T3 & 2,01 \\
\hline T4 & 1,96 \\
\hline T5 & 1,92 \\
\hline
\end{tabular}

Nota-se que a densidade da argamassa no estado fresco ficou no intervalo recomendado para aplicações convencionais, sendo classificada como argamassa normal (CARASEK, 2007). Além disso, nota-se que houve pouca variação da densidade de massa da argamassa, devido os materiais adicionados apresentarem massa específica próximas e de utilizar o mesmo traço em massa para sua elaboração, apenas variando água de amassamento. 
Tabela 7. Densidade de massa teórica das argamassas sem vazios

\begin{tabular}{c|c|c|c|c}
\hline Traço & $\begin{array}{c}\text { Massa seca componentes } \\
(\mathbf{g})\end{array}$ & $\begin{array}{c}\text { Massa de água } \\
(\mathbf{g})\end{array}$ & $\sum(\mathbf{g})$ & $\begin{array}{c}\text { Densidade de massa teórica } \\
\left(\mathbf{k g} / \mathbf{m}^{3}\right)\end{array}$ \\
\hline Ref. & 4563,48 & 855,00 & 5418,48 & 2,24 \\
\hline T1 & 3984,16 & 760,00 & 4744,16 & 2,19 \\
\hline T2 & 3874,50 & 780,00 & 4654,50 & 2,15 \\
\hline T3 & 3764,85 & 800,00 & 4564,85 & 2,12 \\
\hline T4 & 3655,20 & 880,00 & 4535,20 & 2,05 \\
\hline T5 & 3545,54 & 920,00 & 4465,54 & 2,01 \\
\hline
\end{tabular}

Tabela 8. Propriedades da argamassa no estado fresco

\begin{tabular}{c|c|c|c}
\hline Traço & $\begin{array}{c}\text { Teor de Ar Incorporado } \\
\text { (AI) (\%) }\end{array}$ & \% em Vol. Pasta & \% em Vol. Agregado total \\
\hline Ref. & 12,54 & 25,01 & 74,99 \\
\hline T1 & 9,81 & 26,56 & 73,44 \\
\hline T2 & 7,70 & 27,50 & 72,50 \\
\hline T3 & 5,10 & 28,48 & 71,52 \\
\hline T4 & 4,63 & 30,43 & 69,57 \\
\hline T5 & 4,32 & 31,80 & 68,20 \\
\hline
\end{tabular}

$\mathrm{O}$ teor de ar incorporado foi diminuindo à medida que o teor de CBC aumentou, da mesma forma que o volume de pasta (cimento + água) também aumentou. $\mathrm{O}$ teor de ar incorporado em argamassas, embora favoreça a trabalhabilidade da mesma, atua de forma prejudicial em relação às resistências mecânicas.

Tabela 9. Retenção de água

\begin{tabular}{c|c|c}
\hline Traço & Retenção de água média (\%) & Desvio padrão \\
\hline Ref. & 99,37 & 0,03 \\
\hline T1 & 99,95 & 0,04 \\
\hline T2 & 99,71 & 0,07 \\
\hline T3 & 95,94 & 0,05 \\
\hline T4 & 94,66 & 0,04 \\
\hline T5 & 90,21 & 0,06 \\
\hline
\end{tabular}


A respeito da retenção de água, os traços produzidos apresentaram resultados superiores a 90\%, caracterizando esses traços como uma argamassa de alta retenção, fato que é desejável de acordo com a ABNT NBR 13277/2005, pois a retenção de água influi nas reações químicas dos aglomerantes da argamassa influenciando, assim, nos resultados de resistência mecânica, aderência e durabilidade. Nota-se, conforme segue na Tabela 9 e na Figura 4, que a retenção de água foi diminuindo conforme o teor de ar incorporado também diminui, e conforme o volume de pasta aumentou.

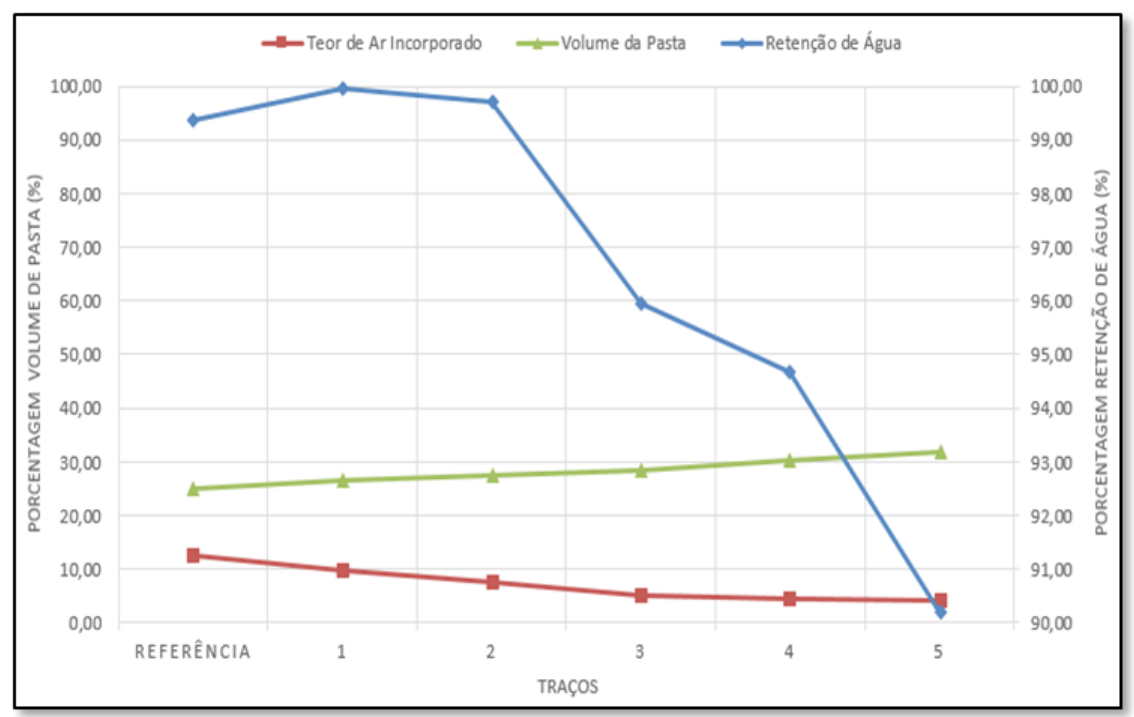

Figura 4. Análise gráfica dos valores de teor de ar incorporado, volume de pasta e retenção de água de cada traço

Os corpos de prova prismáticos moldados, Figura 5, após 28 dias em câmara úmida foram rompidos, obtendo os valores de resistência à tração na flexão e à compressão axial dos corpos de prova, Figura 6 e Figura 7. 


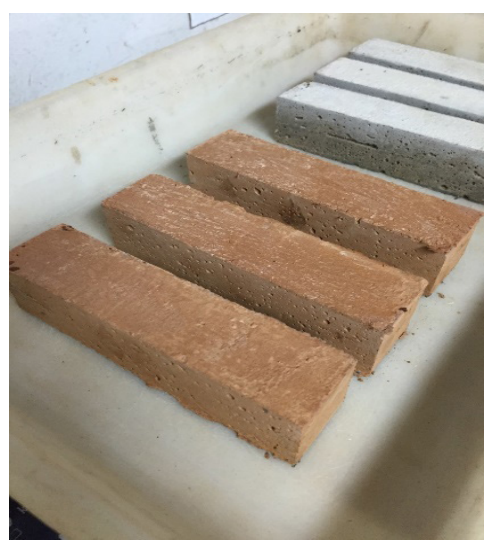

Figura 5. Corpos de prova prismáticos

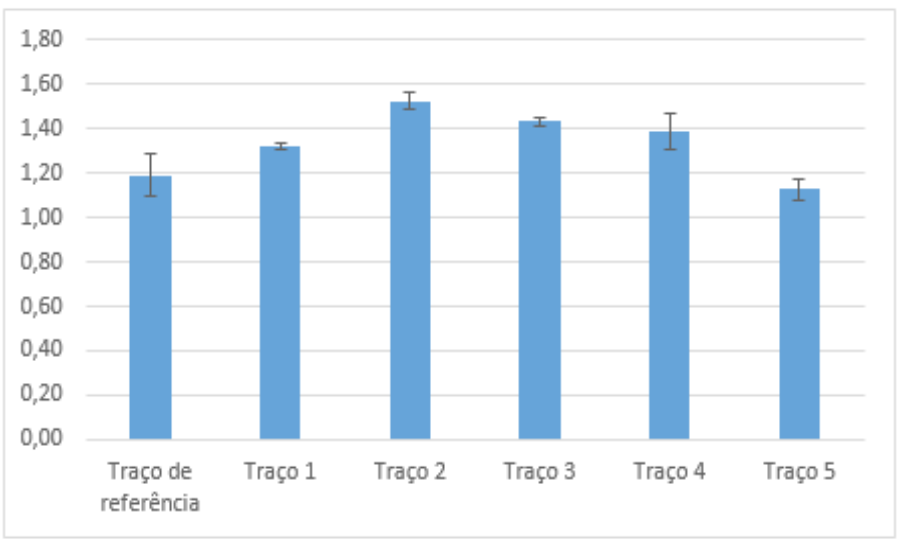

Figura 6. Gráfico dos valores da resistência à tração na flexão (MPa)

Nota-se que não houve prejuízo na substituição da areia natural por RCC e CBC em nenhum traço, e todos estes se enquadram na mesma classe. $\mathrm{O}$ traço composto por 100\% de CBC (T5) não apresentou melhoras significativas em relação ao traço de referência, já os outros traços garantiram melhoras no desempenho. 


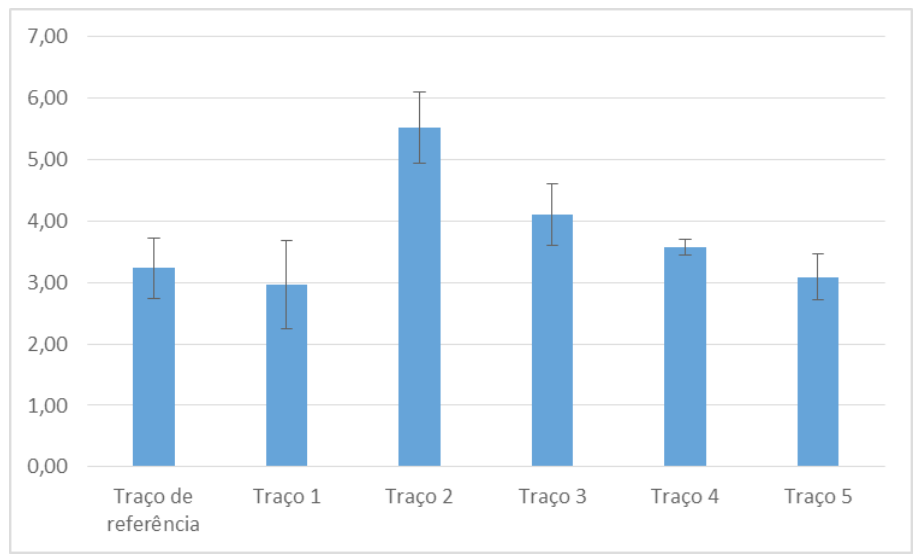

Figura 7. Gráfico com os valores da resistência à compressão (MPa)

Nota-se que não houve prejuízo na substituição da areia natural por RCC e CBC em nenhum traço. Os traços compostos por 100\% RCC (T1), 25\% RCC e 75\% CBC (T4), 100\% CBC (T5) não apresentaram melhoras significativas, porém atingiram valores semelhantes aos do traço de referência. Entretanto, houve uma melhora expressiva nos traços de $75 \%$ RCC e $25 \%$ CBC (T2), 50\% RCC e 50\% CBC (T3) com um aumento aproximado de, respectivamente, 70\% e 30\% da resistência à compressão. No entanto, destaca-se que nesses traços houve uma redução da quantidade de água e um aumento no consumo de cimento em relação à argamassa de referência.

\section{CONSIDERAÇÕES FINAIS}

Durante a produção das argamassas pode-se verificar que o teor de água nos traços aumentou a medida que adicionou-se $\mathrm{CBC}$, devido esta possuir menor granulometria e um volume de vazios maior que os outros componentes da mistura.

A densidade da argamassa no estado fresco e o teor de ar incorporado ficaram dentro dos parâmetros recomendados para aplicações convencionais, destacando um aumento na densidade dos traços T2 e T3, representando assim um provável aumento da densidade de empacotamento, favorecendo o desempenho 
mecânico da argamassa. Além disso, o teor de ar incorporado diminuiu a medida que a quantidade de $\mathrm{CBC}$ foi incrementada.

Ao contrário da demanda de água, a retenção de água da argamassa diminuiu a medida que a proporção de CBC aumentou, porém manteve-se acima de $90 \%$ em todos os traços, atingindo valores que as caracterizam como argamassas de alta retenção, fato que é desejável melhorando a trabalhabilidade, resistência mecânica, durabilidade e aderência.

O desempenho das argamassas de revestimento com utilização de RCC e CBC mostra-se viável como substituto da areia natural quartzosa em argamassas de revestimento. Por meio das análises comparativas empregadas e ensaios realizados notou-se que os traços T2 e T3 apresentaram fatores que ajudaram na melhora do desempenho mecânico, entre estes pode-se citar: diminuição do teor de ar incorporado e uma alta retenção de água. Além de melhorar a resistência à tração e a resistência à compressão das argamassas, o emprego destes tipos de agregados é uma contribuição sustentável ao meio ambiente, diminuindo o consumo de um recurso não renovável e altamente explorado que é a areia natural quartzosa, e dando um destino racional para os RCC e CBC.

\section{AGRADECIMENTOS}

Ao Programa de Pós-Graduação em Engenharia de Construção Civil da UFPR. Ao Departamento de Engenharia Civil da UEM.

\section{REFERÊNCIAS}

ABRECON, 2016. Associação Brasileira para Reciclagem de Resíduos da Construção Civil e Demolição. Disponível em: http://www.abrecon.org.br/. Acesso em: 02 jun. 2016.

AGRICULTURA, 2016. Ministério da agricultura. Cana-de-Açúcar. Disponível em: http://www.agricultura.gov.br/vegetal/culturas/cana-de-acucar. Acesso em: 03 jun. 2016. 
ASSOCIAÇÃO BRASILEIRA DE NORMAS TÉCNICAS. Argamassa para assentamento de paredes e revestimento de paredes e tetos: determinação do teor de água para obtenção do índice de consistência-padrão. NBR 13276. Rio de Janeiro: ABNT, 2005.

ASSOCIAÇÃO BRASILEIRA DE NORMAS TÉCNICAS. Argamassa para assentamento e revestimento de paredes e tetos: determinação da Retenção de água. NBR 13277. Rio de Janeiro, 2005.

ASSOCIAÇÃO BRASILEIRA DE NORMAS TÉCNICAS. Argamassa para assentamento de paredes e revestimento de paredes e tetos: determinação da densidade de massa e do teor de ar incorporado. NBR 1378. Rio de Janeiro, 2005.

ASSOCIAÇÃO BRASILEIRA DE NORMAS TÉCNICAS. Argamassa para assentamento de paredes e revestimento de paredes e tetos: determinação da resistência a tração na flexão e na compressão. NBR 1379. Rio de Janeiro, 2005.

ASSOCIAÇÃO BRASILEIRA DE NORMAS TÉCNICAS. Rochas e solos. NBR 6502. Rio de Janeiro, 1995.

ASSOCIAÇÃO BRASILEIRA DE NORMAS TÉCNICAS. Grãos de solos que passam na peneira de 4,8 mm: determinação da massa específica. NBR 6508. Rio de Janeiro, 1984.

ASSOCIAÇÃO BRASILEIRA DE NORMAS TÉCNICAS. Agregados: determinação de Composição Granulométrica. NBR NM 248. Rio de Janeiro, 2003.

ASSOCIAÇÃO BRASILEIRA DE NORMAS TÉCNICAS. Agregados: determinação da massa unitária e do volume de vazios. NBR NM 45. Rio de Janeiro, 2006.

ASSOCIAÇÃO BRASILEIRA DE NORMAS TÉCNICAS. Agregado miúdo: determinação de massa específica e massa específica aparente. NBR NM 52. Rio de Janeiro, 2009.

ASSOCIAÇÃO BRASILEIRA DE NORMAS TÉCNICAS. Cimento Portland e outros materiais em pó: determinação da massa específica. NBR NM 23. Rio de Janeiro, 2001.

ASSOCIAÇÃO BRASILEIRA DE NORMAS TÉCNICAS. Solo: análise granulométrica. 
NBR 7181. Rio de Janeiro, 1984.

BRASIL. Resolução CONAMA no 307 de 05 de julho de 2002. Estabelece diretrizes, critérios e procedimentos para a gestão dos resíduos da construção civil. Disponível em: http://www.mma.gov.br/port/conama/legiabre.cfm?codlegi=307. Acesso em: 03 jun. 2016.

CASAREK, H. Materiais de construção civil e princípios de ciência e engenharia de materiais. São Paulo, IBRACON 2007.

CORDEIRO, G. C. Utilização de cinzas ultrafinas do bagaço de cana-de-açúcar e da casca de arroz como aditivos minerais em concreto. Tese (Doutorado em Engenharia Civil). Universidade Federal do Rio de Janeiro, Rio de Janeiro, 2006.

FREITAS, M. I. Os resíduos de construção no município de Araraquara/SP. Dissertação (Mestrado em Desenvolvimento Regional e Meio Ambiente) - Centro Universitário de Araraquara (UNIARA), 2009.

GOMES, A. O.; NEVES, C. M. M. Proposta de método de dosagem racional de argamassas contendo argilominerais. Ambiente Construído, Porto Alegre, v. 2, n. 2, p. 19-30, 2002.

LEVY, S. M.; HELENE, P. R. L. Durabilidade de concretos produzidos com resíduos minerais de construção civil. In: III SEMINÁRIO: DESENVOLVIMENTO SUSTENTÁVEL E A RECICLAGEM NA CONSTRUÇÃO CIVIL: PRÁTICAS RECOMENDADAS, IBRACON, 3., São Paulo. Anais [...]. São Paulo: IBRACON, 2000. p. 03-14.

MARIANO, L. S. Gerenciamento de resíduos da construção civil com reaproveitamento estrutural: estudo de caso de uma obra com $4.000 \mathrm{~m}^{2}$. Dissertação de Mestrado (Programa de Pós-Graduação em Engenharia de Recursos Hídricos e Ambiental - Departamento de Hidráulica e Saneamento) - Universidade Federal do Paraná (UFPR), 2008.

MARTINS, C. H.; ALTOÉ, S. P. S. Avaliação da utilização da cinza de bagaço de canade-açúcar na confecção de blocos de concreto para pavimentação. Revista em Agronegócio e Meio Ambiente, Maringá (PR), v. 8, p. 39-54, 2015. 
MARTINS FILHO, S. T.; MARTINS, C. H. Utilização da cinza leve e pesada do bagaço de cana-de-açúcar como aditivo mineral na produção de blocos de concreto para pavimentação. Revista em Agronegócio e Meio Ambiente, Maringá (PR), v. 10, p. 1205-1224, 2017.

NOVA CANA. A produção da cana-de-açúcar no Brasil e no mundo. 2008. Disponível em: https://www.novacana.com/cana/producao-cana-de-acucar-brasil-emundo/. Acesso em: 02 jun. 2016.

O GLOBO. Sustentabilidade. 2015. Disponível em: http://oglobo. globo.com/ sociedade/ sustentabilidade/base-da-construcao-civil-areia-um-dos-recursos-maisvaliosos-explorados-do-mundo-14960573. Acesso em: 03 jun. 2016.

OLIVEIRA, M. S.; SILVEIRA, J. S.; MORATO, J. B.; AVELLAR, G.; VALADÃO, R. C. Impactos ambientais decorrentes da extração de areia, Cachoeira da Prata - MG. In: SIMPÓSIO NACIONAL DE GEOMORFOLOGIA, 9. Anais [...]. Rio de Janeiro, 2012.

PORTAL RESÍDUOS SOLIDOS. Definição de resíduos da construção civil no Brasil. 2015. Disponível em: http://www.portalresiduossolidos.com/definicao-deresiduos-da-construcao-civil-no-brasil/. Acesso em: 03 jun. 2016.

TRISTÃO, F. A. Influência da composição granulométrica da areia nas propriedades das argamassas de revestimento. 1995. 188f. Dissertação (Mestrado) - Universidade Federal de Santa Catarina, Florianópolis, SC.

Recebido em: 05/08/2017

Aceito em: 06/06/2018 